\title{
Diagnosing Marine Piston Engines Driving Generators at Different Operational Loads
}

\author{
Jan Monieta
}

check for

updates

Citation: Monieta, J. Diagnosing Marine Piston Engines Driving Generators at Different Operational Loads. J. Mar. Sci. Eng. 2021, 9, 132. https://doi.org/10.3390/jmse9020132

Academic Editor:

Mohamed Benbouzid

Received: 7 November 2020

Accepted: 23 January 2021

Published: 28 January 2021

Publisher's Note: MDPI stays neutral with regard to jurisdictional claims in published maps and institutional affiliations.

Copyright: (C) 2021 by the author. Licensee MDPI, Basel, Switzerland. This article is an open access article distributed under the terms and conditions of the Creative Commons Attribution (CC BY) license (https:// creativecommons.org/licenses/by/ $4.0 /)$.
Maritime University of Szczecin, Wały Chrobrego 1-2, 70-500 Szczecin, Poland; j.monieta@am.szczecin.pl; Tel.: +48-91-480-9415

\begin{abstract}
Loads at which diagnostic research should be carried out were selected of operational investigation and preliminary diagnostic tests. It is difficult to keep the load constant during operational tests, so there is a need to apply the theory of the experiment. Operational investigation determined, the average and representative loads of tested engines driving generators. In preliminary diagnostic tests, the effects of loading on values of diagnostic parameters in various domains of signals analysis were checked and used to reduce the range the diagnostic research. Besides, the most useful symptoms were selected based on the correlation with the load. The diagnostic of pressure in the injection subsystem and in-cylinder pressure signals were subjected to time frequency analysis. In the principal studies, attempts were made to investigate the value of diagnostic symptoms while maintaining a constant load. For operating marine combustion engines, it is difficult to obtain repeatable test conditions because it is dependent on the principles of engine control and consumption of electricity by shipboard receivers. In operational tests on sea-going vessels, a wireless load measurement system and a system for processing and analyzing the parameters of working and residual processes were used. The wireless simultaneous load measurement system was effective in cases where load indicators and meters were away from the diagnosed objects. A wireless load and selected signals transmission system was used in tests on the ship. The aim of the article is to develop diagnostic models for bringing different test conditions to the common representative and reliable diagnostic decision. The article presents how to adjust diagnostic parameters of the working process, recorded at slightly different loads, to the value of common and equal load. This was done based on the best-fitted approximation model.
\end{abstract}

Keywords: marine generator sets; operational conditions; combustion engine loads; parameters of working processes; diagnostic symptoms; diagnostic models; correction for equal load

\section{Introduction}

At the stage of tender and conceptual designs, the exact determination of the capacity of the ship's power plant is difficult, due to the inability to determine electric power demand of the ship. Even for one type of ship, power distribution differences are relatively large [1].

Generally, the development of ship electrification is observed, different for various types [2,3], which translates into higher demand for electricity, even if innovative devices become more energy efficient.

The authors in [4] indicated that at present the demand for electrical power generated on vessels is significant increased, due to the increase in electrical equipment. An optimal choice of correct and efficient size of generator sets was made using the traditional method of load factors. The authors solved the optimal problem using genetic algorithms.

The load of the internal combustion engine is defined by $[3,5]$ : the mean effective pressure, rotational speed, rate of pressure increases in the cylinder, load distribution procedures, etc. The forces of inertia are related to the movement of the piston-crank system, and their value depends on the rotational speed of the crankshaft [5]. Users avoided 
operating engines at higher loads not to deteriorate their technical state. The choice of engine load can be made by testing: the spectral composition for individual loads or the maximum signal values for individual loads $[4,6]$. The following characteristics groups of internal combustion engines are divided by the independent variable [7-9]:

- speed characteristics;

- load characteristics;

- regulatory characteristics;

- general characteristics, also called universal characteristics.

Load characteristics are intended for evaluation of changes in basic functional indicators depending on the load at a constant rotational speed. They are used primarily to evaluate the engines of power generator sets or when the rotational speed changes slightly, while the rotational speed can differ up to $\pm 3 \%$ [8].

For the acquired symptoms to be reliable, the measurements must be carried out under repeatable conditions and in accordance with the requirements $[5,10]$. The diagnostic parameters in operation for each cylinder of combustion engine depend on instantaneous load. Therefore, simultaneous measurement of each cylinder and load of an internal combustion engine is required [11], and when the loads are not equal, the diagnostic parameters need to be reduced to common loads for individual cylinders.

The remainder of this paper is organized as follows. In the next section, examples of shipboard research into internal combustion engine loads are given. Then examples of load tests on marine internal combustion engines are presented. The diagnosis of marine self-ignition engines at various loads was described. Then, the method of preliminary and main research with the use of experiment planning is presented. The next part brings the results of testing operational loads of marine engines driving generators. The main part includes the results of the research on the impact of load on the values of diagnostic parameters and the method of calculating the value of the diagnostic symptom for unique loads based on the diagnostic model. The paper ends with conclusions.

\section{Examples of Shipboard Research into Internal Combustion Engine Loads}

\subsection{State of the Knowledge and Technology}

Some authors, as well as manufacturers of piston marine engines, recommend that measurements time waveforms of pressure in engine cylinders be performed at high crankshaft speeds and large loads $[8,9,12,13]$. Manufacturers of marine self-ignition combustion engines [14] indicated that low load operation is problematic because generator sets are often oversized in relation to the actual load.

Low load of internal combustion engines running for long periods of time can lead to changes of technical state. Low load operation of self-ignition engines occurs when operations at load does not exceed $40 \%$ of maximum continuous rating [13].

Fixed speed auxiliary engines and gensets with common rail, either with modular common rail system (MCRS) or High Pressure Common Rail (HPCR), should not run for more than eight hours at a time at less than $10 \%$ of prime power or more than $24 \mathrm{~h}$ at a time at less than $30 \%$ of prime power [15].

Cummins Marine recommends that low load operations (10-30\% of prime power) for longer periods of time (maximum 8-24 h) depending on engine type should be followed by at least $30 \mathrm{~min}$ of high load operation (higher than $50 \%$ of rated power) [16].

According to the class requirements, the move frequency of changing step loads in marine power system is limited to $\pm 10 \%$ [17]. Then the on-line system can disconnect non-essential receivers and unload the network, which not always is the case. Generator sets usually are programmed to carry a maximum of $110 \%$ load in a failure state [18].

In steady load states, the engine operation indicators such as cylinder temperatures of working medium and rotational speed remain constant or change periodically. There 
are relations between the parameters characterizing the combustion engine operation in steady-state conditions [19]:

$$
\mathrm{N}_{\mathrm{e}}=\frac{\pi D^{2} \operatorname{Sip}_{e} n_{o} z}{240}=\frac{\pi D^{2} \operatorname{Sip}_{i e} \eta_{m} n_{o} z}{240}=\frac{G_{e} C_{v} \eta_{e}}{3600},
$$

where: $\mathrm{N}_{\mathrm{e}}$-effective power, $D$-cylinder bore, $S$-piston stroke, $i$-number of cylinders, $n_{0}$-rated crankshaft speed of engine, $z$-work cyclical factor, $p_{e}$-brake mean effective pressure, $p_{i}$-mean indicated pressure, $\eta_{m}$-mechanical efficiency, $G_{e}$-fuel consumption per hour, $C_{v}$-fuel heating value, $\eta_{e}$-brake thermal efficiency.

The mean indicated pressure can be calculated from the cylinder pressure profile:

$$
p_{\mathrm{i}}=\oint P_{\mathrm{s}} d V i
$$

where: $P_{s}$-instantaneous pressure of gases in the cylinder, $d V$-change of displacement volume:

$$
p_{e}=p_{i} \eta_{m}
$$

Taking into the mechanical efficiency $\eta_{m}$ measured or adopted and the efficiency of the electric generator $\eta_{G}$, enables calculation of electric power:

$$
N_{e l}=\eta_{G} \eta_{m} i N_{i},
$$

where: $N_{i}$-cylinder indicated power output. Effective power (useful power) $N_{e}$ is the power that the engine transfers to the power receiver in the operating conditions.

Changes in engine load are caused by the following factors [5,19]:

- changes in engine or receiver settings to change the internal combustion engine from one steady state to another;

- periodical or non-periodical changes in the time when external factors affect the working conditions;

- unfitness of components of an internal combustion engine, receiver, or control systems that have the position of the control system components and the set external conditions, cause periodic load changes.

The following operational load conditions of internal combustion piston engines are distinguished [5]:

- steady states,

- transient states,

- transitory processes.

The operation of an internal combustion engine in transient states is characterized by:-lack of balance between the amount of energy supplied to and transferred from the internal combustion engine:

$$
Q_{i} \neq Q_{o},
$$

- lack of torque balance between the internal combustion engine and the power receiver:

$$
M_{e} \neq M_{r},
$$

- lack of torque balance between turbine and compressor:

$$
M_{t} \neq M_{c}
$$

where: $Q_{s}, Q_{0}$-heat supplied and removed from the system, $M_{s}, M_{0}$ - engine and receiver torque, $M_{t}, M_{c}$-turbine and compressor torque.

The publication [3] shows that marine high-speed self-ignition combustion engines for high-speed ships, passenger vessels, and ferries were exploited in difficult conditions of frequent start-ups, fast acceleration, and shut down right after heating. To obtain the load 
characteristics of high-speed engines in motion, full-scale measurements of in-cylinder pressure of the combustion engines were recorded uninterrupted from engine start-up to shut down.

Paper [20] contains a numerical analysis of efficiencies and non-measured operational parameters for the marine two-stroke slow speed turbocharged self-ignition combustion engine 6S50MC MAN B\&W. The analysis was based on a measurement set performed at different relative loads of the engine.

MAN Diesel 6S50MC-C two-stroke marine self-ignition engine was tested in paper [12]. The intensity of deformations due to thermal load, mechanical load and combined loads were studied. Based on the temperature field, the thermal intensity was obtained in the ANSYS program. Then the distribution of stress and strain the under mechanical load and combined loads was investigated.

The characteristics of particle emissions from a marine self-ignition engine operated at low loads on different distillate and residual fuels include particle number and mass, size distribution, volatility, and chemical composition [20,21]. The test in laboratory conditions revealed unfavorable levels of particle emissions from marine combustion engines in ports and coastal areas where lower engine loads are common. Future environmental anti-pollution requirements for watercraft force further fuel savings leading to reduced exhaust gas emissions [21].

Publications $[22,23]$ presented the optimization of operation procedures for the minimization of fuel consumption. Their method is intended as an aid in a design of power management system.

In this paper [24] we test and establish a nonlinear mathematical model of vessel power system, and then based on the Hamilton energy method, we design a nonlinear excitation controller of self-ignition speed coordination set. The simulation results show that the passivity-based controller will be stable in the system during no-load start-up, sudden load peaks and network connection power generation.

\subsection{Estimation of the Capacity of Ship's Power Plant and Its Generator Sets}

At the design stage, nominal values of all electricity consumers are determined. However, it is still difficult to accurately determine the degree of use of the installed capacity (load level of individual devices), their working time, the frequency of switching on and off, and the simultaneity of their operation. If the $C_{l}$ load coefficients and the simultaneity of $C_{c}$ [2] operation are estimated, then the necessary power capacity of the ship's power plant can be determined. The load factor is expressed by the dependency [25]:

$$
C_{l}=\frac{N_{e r}}{N_{e n}},
$$

where $N_{e r}$ - actual power input by the receiver working in a given operating state, $N_{e n}-$ power rating of the receiver.

The coefficient of simultaneity is an estimate that indicates $C_{c}$ the probability of simultaneous operation of individual receivers [2]. For an individual device, it can be interpreted as the probability of switching it on. The calculation of the balance sheet can be carried out based on knowledge of the operational factor of use of the installed power [25]:

$$
C_{o i}=C_{l} C_{s,}
$$

where $C_{o i}$-operational factors of use of the installed capacity, $C_{s}$ - coefficient of simultaneous work of individual receivers.

The values of load coefficients and simultaneity of work for devices and groups of devices and operating states should be determined by means of measurements performed during operational voyages. The use of load and simultaneity factors requires the knowledge of their value of many different receivers. Initial calculations of the total power of the ship's power plant make use of data from similar ships. Alternatively, empirical formulas 
for different types of ships can be used, based on a statistical analysis of the power plant of similar ships. For an example, for a bulk carrier, the power of a power generating plant can be calculated from the formula $[26,27]$ :

$$
N_{e l}=c+d N_{m d}
$$

where $c, d$-coefficients in the linear regression model determined by the method of least squares [26,27], $N_{m d}$-power on the main drive shaft or shafts.

One study [28] presented modeling and autonomous performance of real-time load scheduling for an offshore supply vessel aimed at minimizing the specific fuel oil consumption for better efficiency. The photovoltaic-based energy storage system has been used as an option to meet short time load demand in transient states.

In shipping, the generator sets often work in parallel at small load far from optimal points. Improving work efficiency and reducing fuel consumption requires the use of only one generator when a ship is at sea [29].

Recent years have brought an increasing interest in energy efficiency and environmental issues. The International Maritime Organization has adopted measures to reduce emissions from new and existing ships [30]. The aim is to stimulate technical developments and innovation in design as well as in management of operation ships.

Sørensen [31] described design problems with real-time control and monitoring systems and addressed operational systems management systems as well. Marine operations with dynamic positioning of floating objects are presented, where the methodologies are suitable for other applications and operation conditions.

One article [32] presented elaborated solutions where large electric energy storage is used to take part of the load during the time interval from damage of the generator and loading of a stand-by generator. A simulation model was developed to collect electricity in the event of a power drop caused by a failure. The electricity produced and transmitted on ships can be of different quality. Improper quality of electricity is associated with load asymmetry, its non-linearity and variability even under steady-state operation of internal combustion engines.

\section{Diagnostics of Marine Diesel Engines at Various Loads}

One article [33] presented a methodology for diagnosing the operating conditions of marine internal combustion engines by means of non-invasive measurements of noise and vibration on the cylinder head. The measured values for various engine loads, made up the reference values which were compared with the measured values.

One work [34] presented the results of vibration signal measurements on the cylinder head to assess the combustion process. The vibration signal was measured with a vibration displacement sensor, a vibration velocity sensor, and a vibration acceleration sensor. Based on the test results, the authors have shown that the vibration velocity sensor is the best sensor for diagnosing the combustion process.

The use of in-cylinder pressure rate for diagnostics of marine engine tuning leads to incorrect results if the load changes. The authors of articles $[9,10,32,35]$ developed a new calculation method to allow for load change effects. For diagnosing purposes, two in-cylinder pressure sensors for simultaneous measurement must be used instead of measurements in subsequent cylinders.

Ome work [11] presented a nonlinear model of a two-stroke low speed marine selfignition engine using the torque between the generator and combustion engine. In the analysis, the maximum error between the model and experimental data has been reduced to $1.5 \%$. The neural network simulates the mean power of each cylinder with an error less than $1 \%$ for any load and engine condition.

Zadrag presented empirical research of a marine combustion engine using the theory of experiment [36]. The author attempted to analyze multi-equation regression models seeking relations between input and output quantities. 
In some marine electric power supply systems, self-ignition engines are used to drive one synchronous generator and the main propeller through transmission gear. In [37] a model was elaborated for different states, including the dynamics of the self-ignition engine and synchronous generator shaft.

The optimization of engine control parameters is highly affected by the combustion engine load. The author [38] proposed classification of engine load in real time based on detected signals. Engine loads are divided by, trained using processed, real data from measurements an artificial neural network was. The described optimization of combustion engine control parameters has a major impact on actual engine load.

This article by Bashan and Demirel [39] presented a method to evaluate the critical operational faults in marine diesel generators. The method allows identifying and analyzing important technical states of marine diesel generators for the cause-effect relationship of diagram.

For diagnostic purposes, the choice of an internal combustion engine load can be made by examining changes in time histories or the spectral composition of parameters for individual loads, analysis of the maximum signal values for individual loads, etc. [7,40]. Tomaszewski and Szymanski [6] proved that the combustion engine load does not significantly affect the shape of the spectrum of the vibration signal. The effect of loading on the values of diagnostic parameters, spectral composition, etc., was determined in diagnostic tests $[7,38]$. Pietak examined self-ignition combustion engine in transient conditions under dynamically changing loads [41].

One article [37] described the application of an improved diagnostic method for the main engine and the auxiliary sets of a merchant marine vessel. The diagnostic method is based on a thermodynamic simulation model where the existing two-zone model is replaced by a multi-zone one. With this model, tuning of operation conditions is not need.

In some studies, data from acceptance tests were used to develop diagnostic models $[9,10,25,42]$. One article [10] presented the application of a model of a marine internal combustion engine with a turbocharger including their interactions. A simulation model was developed based on data from acceptance tests and its ability to predict the performance of an internal combustion engine under load change conditions of $40-100 \%$ was examined.

That by Chena and others [43] presented a method for machine diagnostics in an unsteady working condition using instantaneous optimal power spectrum and genetic programming. The authors applied frequencies of the different machine technical states from registered vibration signals to identify damages by relative crossing data.

\section{Research Method}

In diagnostics of piston combustion engines, it is not justified to determine all possible points of functioning the object, because their working characteristics are different. In this work, research was undertaken to determine the points of load characteristics because they were mainly aimed at internal combustion engines driving generators. Since it is difficult to obtain repeatable loads in operation, the aims of this article are wireless the wireless techniques and models to diagnose marine piston engines driving generators at different operational loads. It is very interesting and important issue in operation condition of facilities.

The choice of the load at which diagnostic tests should be carried out was based on operational examination in conditions of sea-going vessels and preliminary tests. The most frequent and average loads of internal combustion engines driving generators were determined for various sea-going vessels and various types of piston combustion engines from different manufacturers. The load values determined in this way were central values during the planning of diagnostic experiments. Planning experiments are applicable in cases where the value of a certain factor cannot be kept constant (such as the load on the generator set). In diagnostic tests it allowed identifying the effect of load on diagnostic parameter values, spectrum composition, wavelet analyses, etc. $[7,40]$. 
Some parameters of marine engines depend on external conditions, such as ambient temperature, barometric pressure, and relative humidity. These are the parameters of the reference conditions, and the ships were equipped with air conditioners. Some parameters of marine engines depend on external conditions, therefore reference parameters were measured and compared to ISO 3534-3 standard reference conditioning $[7,9,10]$.

The transposed quantities are denoted by the index " $r$ " and are called reduced parameters, e.g., $N_{e r}$-effective power reduced under normal conditions. The formula for converting effective power to normal conditions according to the international organization of combustion engine manufacturers [9]:

$$
N_{e r}=\frac{1}{\alpha} N_{e}
$$

where $\alpha$ is a conversion factor.

The coefficient a depends on the current mechanical efficiency of the engine and weather conditions, the engine's equipment with a charging air supercharging, cooling system, and the power limitations due to the permissible thermal load. The measurements were carried out in natural conditions during ships stays in ports, shipyards and during voyages, as well as in laboratory conditions. Variable and repeatable loads of generator sets were assured by switching on ship's electricity consumers or loading with a water resistor. However, it was virtually difficult to provide the same loads due to the random power consumers were turn on and off in subsequent measurements. Diagnostic parameters depend on the values of supply and steering quantities, load, technical condition, and unavoidable interference magnitude.

The input signal vector $I_{q}$ can be written [44]:

$$
I_{q}(\tau, \theta)=[F(\tau, \theta), N(\tau, \theta), Z(\tau, \theta)]^{T},
$$

where: $F(\tau, \theta)$-enabling targeted action on the functioning of the diagnosed internal combustion piston engine (control, power, fuel, etc. conditions, $N(\tau, \theta)$-interference magnitude that are not directly measured, $Z(\tau, \theta)$-measurable and non-controllable

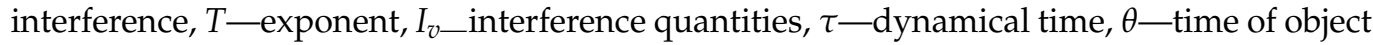
existence.

The power supply and steering values can be kept constant: $F(\tau, \theta)=$ const. and $T_{s}$ $=$ const., interference values can be minimized $N(\tau, \theta)$ and $Z(\tau, \theta)$ min (Figure 1 ). If the technical condition does not change $T_{S}=$ const., then the diagnostic parameters of the internal combustion piston engine depend mainly on the load, which was used in the study for planning experiments and pre-selecting diagnostic parameters:

$$
P_{d}=A(r) N(\tau, \theta)+Z(\tau, \theta), T_{s}=\text { const. }
$$

where: $P_{d}$ —diagnostic parameter, $A(r)$ —algorithm, $T_{s}(\tau, \theta)$ —technical state.

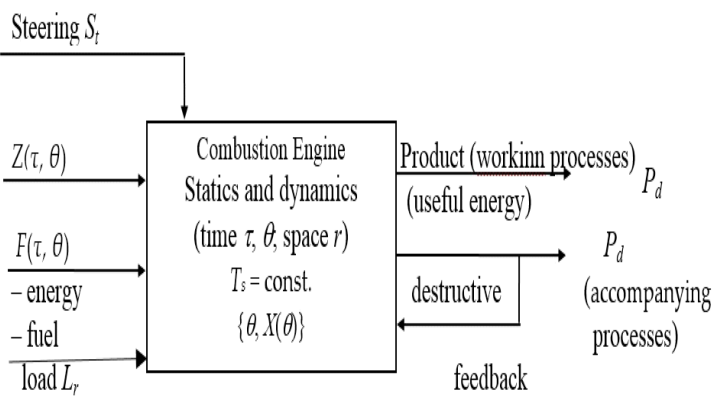

(a)

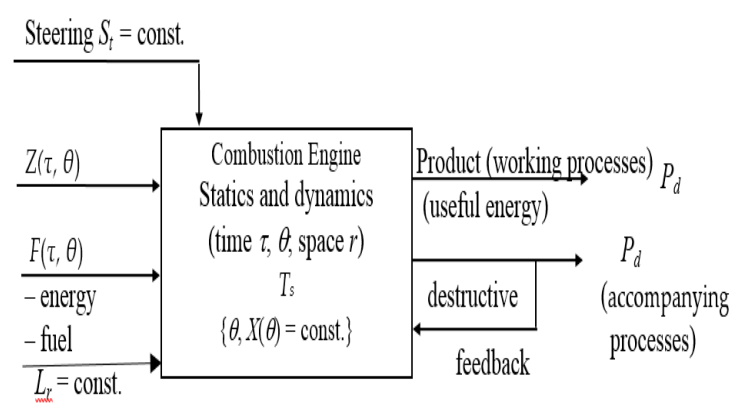

(b)

Figure 1. Diagnostic model in preliminary (a) and principal research (b). 
However, if the load is kept constant, the diagnostic parameters will depend mainly on the technical state:

$$
P_{d}=A(r) N(\tau, \theta)+Z(\tau, \theta), L_{r}=\text { const. }
$$

where $r$-spatial coordinate.

The last relationship was used in the principal studies, and other values of the test conditions were treated as disturbances so methods of minimizing them were sought. In this way the impact was determined as significant or not and diagnostic models were elaborated.

Both preliminary and principal research were conducted using experiment planning. Diagnostic tests of marine diesel engines, mainly power generators, were carried out in two stages and also laboratory conditions at the Maritime University of Szczecin and in shipboard operation on ships of large world ship-owner. Research objects were seagoing vessels, bulk carriers. One ship usually has one main propulsion engine and three generating sets, sometimes of different powers. Some ships were equipped with shaft generators of main engines. Operational tests of 58 marine diesel engines driving generators were carried out. Table 1 gives examples data from tested ships.

Table 1. Characteristic data of the Handy-size vessel.

\begin{tabular}{ccc}
\hline Characteristic & Value & Measure \\
\hline Length & 189.97 & $\mathrm{~m}$ \\
Breath & 28.50 & $\mathrm{~m}$ \\
Draft & 10.3 & $\mathrm{~m}$ \\
Dead weight tonnage & 37,964 & $\mathrm{t}$ \\
Speed (max/average) & $11.9 / 11.5$ & $\mathrm{kn}$ \\
Main engine & 1228 & $\mathrm{~kW}$ \\
Diesel generators & $3 \times 680$ & $\mathrm{~kW}$ \\
\hline
\end{tabular}

In the preliminary research the output quantities were measured (diagnostic parameters, engine working parameters) at different values of input magnitudes (relative load, position of setting elements), in the presence of quantities accepted as constant (rotational speed of the crankshaft, technical state of self-ignition engine) and minimizing the level of interference (engine working parameters, ambient reference parameters, effects of other marine facilities). Preliminary experimental diagnostic studies, the influence of the frequency band on the values of diagnostic parameters was checked and an optimal band of $0-100 \mathrm{~Hz}$ was selected.

This frequency band was useful for pressure signals in the injection subsystem, pressure in cylinders of internal combustion engines and for vibration displacements of elements of the injection subsystem [7]. The cylinder pressure waveform was chosen as an example signal in discussing the principles of the analysis for various reasons: expected processing of such signals, and good knowledge of the physics of the process, sources and forms of interference, enabling a reliable assessment of the results obtained.

The effect of the frequency band in the analysis was investigated for the mentioned signals. A spectral analysis showed that for these signals there are no significant components in the frequency band higher than $100 \mathrm{~Hz}$ (Figure 2b). In the lower frequency band (0-100 $\mathrm{Hz}$ ) there is a greater resolution, but at the same time deviations from the set rotational frequency are visible. In the higher frequency band $(0-2.5 \mathrm{kHz})$, the effect of the rotational frequency deviation is not visible, but a smaller variation in the results is obtained, as determined for example by the sensitivity factor in [7]. A Nyquist sampling criterion was met during sampling, i.e., the signal frequency did not exceed half the sampling frequency. 


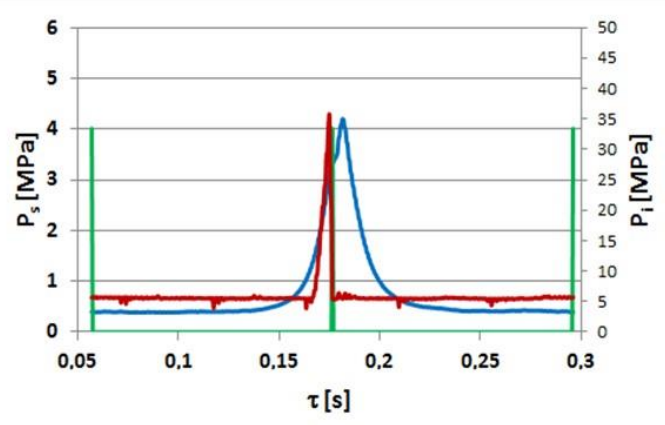

(a)

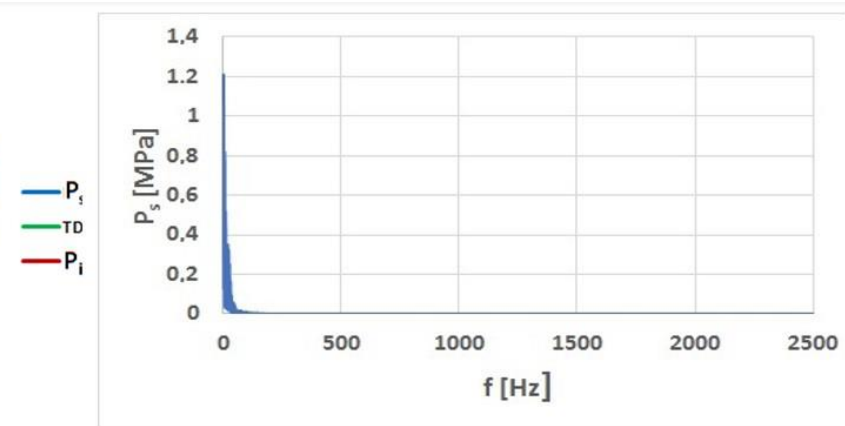

(b)

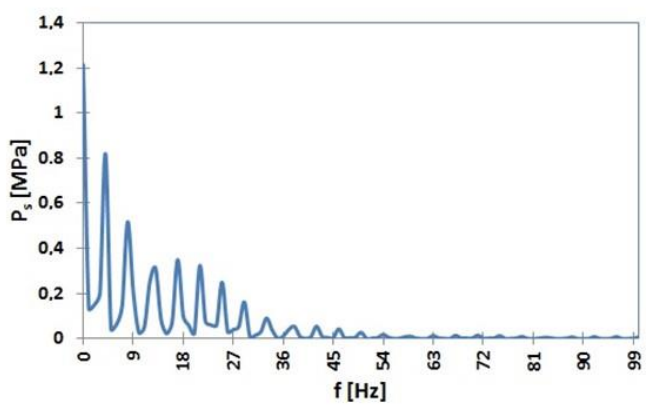

(c)

Figure 2. The time $\tau$ waveforms of the pressure signal in the injection subsystem $P_{i}$ and the in-cylinder $P_{\mathrm{S}}$ of the marine internal combustion engine (a), example analysis in the frequency band $0-2.5 \mathrm{kHz}(\mathbf{b})$ and a fragment of the spectrum from Figure $2 \mathrm{~b}$ in the frequency band $0-100 \mathrm{~Hz}(\mathbf{c})$.

The wavelet transform was used to reduce signal interference by decomposition (Figure 3) and to search for new diagnostic parameters [7,40]. This recording presents way how to carry out a decomposition and synthesis of an original signal. This way the signal useful in pressure distribution in cylinders was separated from the interference. Wavelet decomposition also allows detecing the influence of load changes on the values of signals in the analyzed frequency band. In [7], the author presented the research on various wavelet measures to search for the most useful diagnostic symptoms.

Preliminary tests were performed on marine self-ignition engines in laboratory and seagoing vessels conditions, i.e., power plants of bulk carriers. The tests consisted of measuring signals of working and accompanying processes in individual cylinders and analyzing them at various engine loads and checking their correlation with load.

The fundamental part contained the recording of output data (diagnostic symptoms, engine parameters) when the input data (state of the self-ignition engine, rotational speed, type and properties of liquid petroleum fuel, control settings) and the influence of the values adopted as constant (relative load of engine, rotational speed of crankshaft) and the minimum level of interferences [7].

In the fundamental research, the technical state of individual cylinders was evaluated at a selected constant load. The article contains the results of investigation of the operating loads of self-ignition engines driving generator sets produced under the license of the Wärtsilä and MAN Energy Solutions company, installed on various vessels. Other parameters of the test conditions were treated as disturbances and methods were sought to minimize them. Technical state and efficiency of an internal combustion engine are significantly influenced by its load, hence the need to carry out tests at a controllable and repeatable load. The principal research aim was the diagnostics of the technical condition of individual cylinders while striving for the same load. 


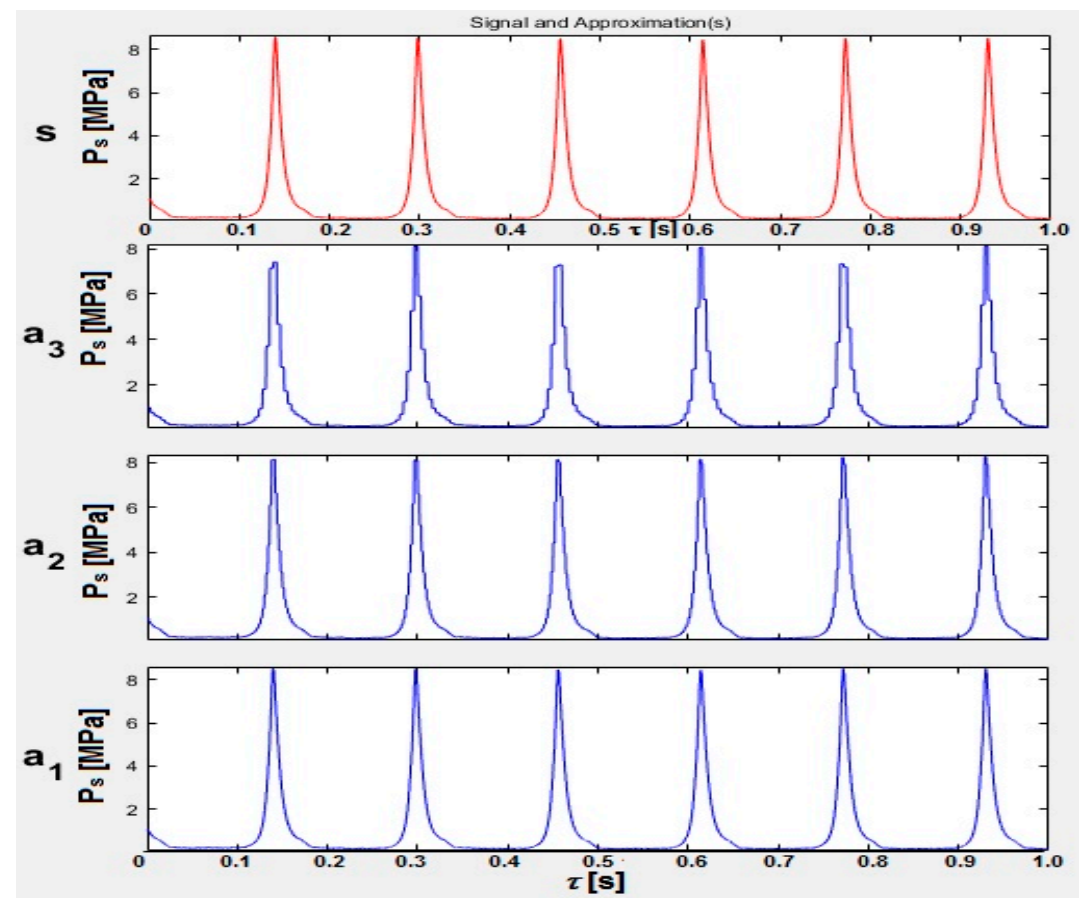

Figure 3. Fragment of the decomposition using the Daubechies wavelet $(\mathrm{db})$ of the pressure waveform signal in the cylinder at decomposition level 5 in the frequency band 0-2500 Hz.

Tests included measurements of time-pressure waveforms in the engine cylinders and the fuel injection subsystem, applying resistive pressure sensors and contactless photo optical crankshaft position sensors. The scheme and elements of the measuring track along with the description are presented in Figure 4. Shipboard tests were difficult as load indicators of internal combustion engines driving generators were located at a considerable distance in the from them in the Maneuvering-Controlling Center, sometimes on a different deck, which required the use of the Sygonix 16885Y1 wireless monitoring system with radio transmission of data. Using a frequency of $2.4 \mathrm{GHz}$, it has four transmission channels and a range of up to $300 \mathrm{~m}$. An external camera with night vision function and a sensor is shown in Figure 5a, and a monitor with a built-in recorder in Figure 5b.

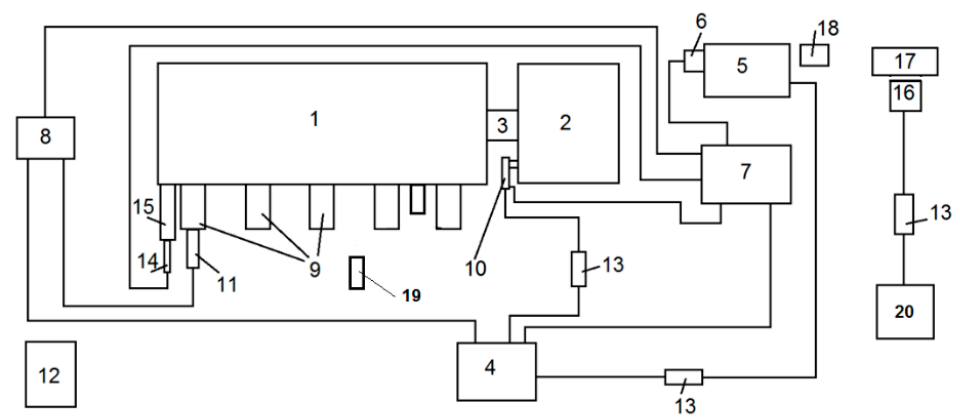

Figure 4. The scheme of test track: 1-combustion engine, 2-generator, 3-the shaft connecting the engine and generator, 4, 13, 14-power supply, 5-laptop, 6-analog to digital converter, 7terminal connection, 8-amplifier, 9-indicator valves, 10-photo optical crankshaft position sensor, 11-resistance pressure sensor, 12-ambient parameter meter, 15-pressure sensor in injection subsystem, 16-camera, 17-engine load indicator, 18-monitor, 19-non-contact temperature meter, 20-antenna. 


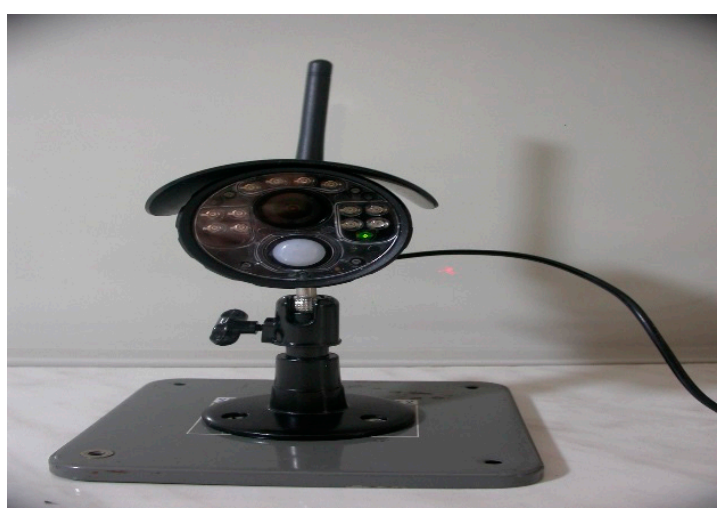

(a)

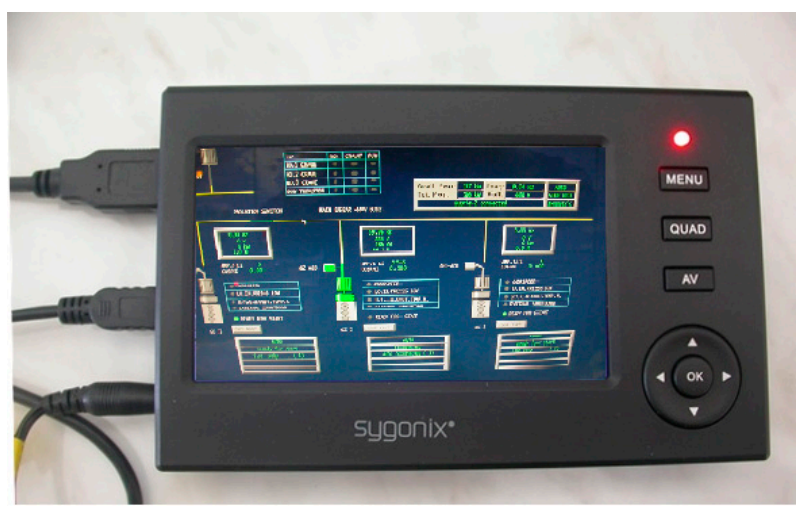

(b)

Figure 5. Recording camera (a) and monitor (b) showing generating set loads.

Relevant analyses were based on indications of electricity meters of individual generating sets and counters of the working hours of combustion engines driving the generators. There also made use of registered loads of generating sets on some ships and an attempt was made to digitize the visualizations. The time waveforms of load of a power generator set driven by a MAN B\&W internal combustion engine are shown in Figure 6a. During the tests, measurements were also made in transient states at lower loads (Figure 6b). Figure 6a shows that the active power oscillates at around $180 \mathrm{~kW}$, which is about $36 \%$ of the rated power, i.e., it is a low load [10]. Also, measurements at $0 \%$ load before connection to network or stopping the generator set. As suggested by manufacturers, generators should be operated at least between $15 \%$ and $90 \%$ of their nominal power $[4,14]$.

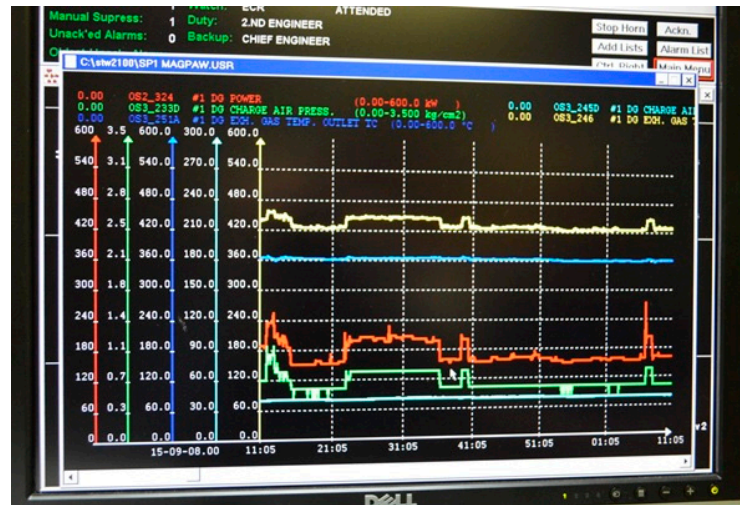

(a)

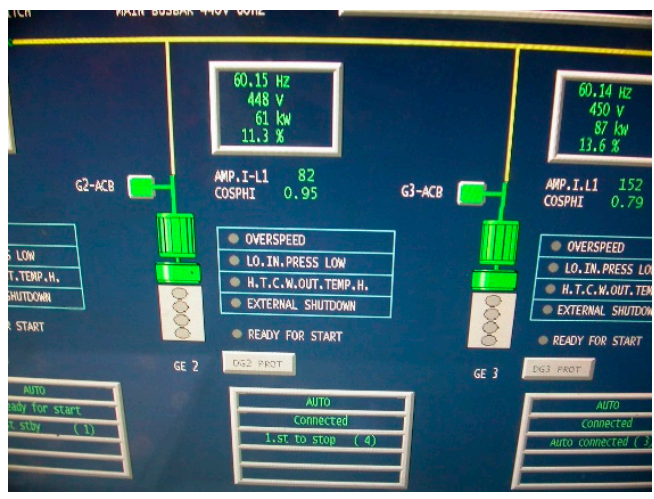

(b)

Figure 6. Recorded loads of a generating set (a) and operation of two generating sets at a load of $11.3 \%$ and $13.6 \%$ in transient states (b): $D G$-active power of the generating set in $\mathrm{kW}$.

\section{Selected Research Results}

\subsection{Load Tests for Power Generating Sets}

In the preliminary tests central values were 0 and $100 \%$ of the relative load. Another central value of the fuel unit set was determined in operational investigations [1]. Based on entries in engine log-books and computer-based surveillance system records, loads per one engine were calculated: engine type 6AL20/24 installed on B-361 and B-542 type ships of one of the world's largest ship owners [1]. Collected data covered every third month in a year, four months in total. The investigations showed that the most common load was $58 \%$.

Figure 7a shows recorded diagnostic parameters at loads during one of the tests in the conditions of a ship docked in a shipyard. Most of the loads were different. Figure $7 \mathrm{~b}$ displays fluctuations in of the time-pressure waveforms in the cylinder of an internal 
combustion engine in dynamic time $\tau$ as a result of changes in engine load. A long-time window (10 s) will reveal the influence of the load on the pressure signal pulses in the cylinder. Time and spectral averaging of the signals reduces slight load variations.

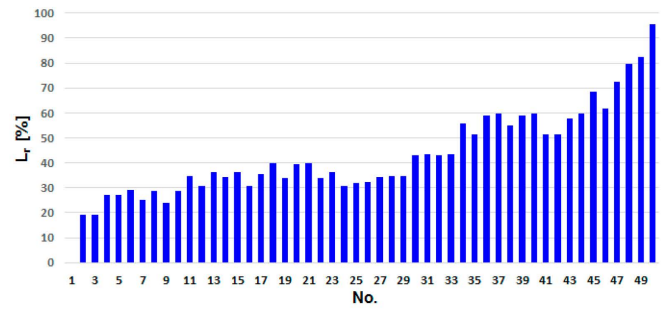

(a)

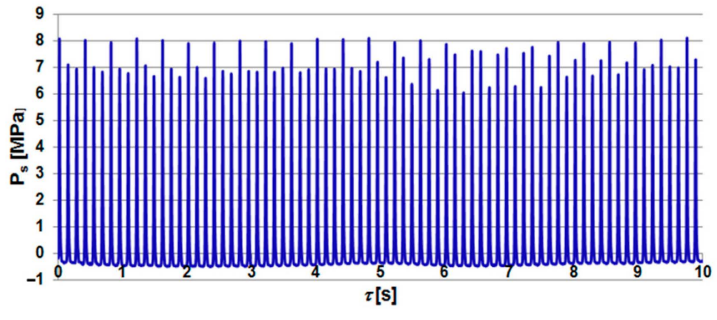

(b)

Figure 7. Systematized recorded load scenarios during exemplary tests on a seagoing ship (a) and time waveforms of pressure fluctuations of in the cylinder of an internal combustion engine in dynamic time as a result of load changes (b).

An average load of the generating set $L_{r a}$ during operation was calculated from the relationship:

$$
L_{r a}=\frac{1}{\tau} \sum_{i=1}^{n} L_{r i}
$$

where $L_{r a}$-the average load of the generating set, $L_{r i}$-value of the $i$-th load, $\tau$-total working time on all workloads tested $\left(\tau=\sum_{i=1}^{n} \tau_{i}\right), \tau_{i}$-working time at the $L_{r i}$ load.

Calculations of the average load for bulk carriers were based on the readouts from the electricity meters of each generating set and the working hour counters of internal combustion engines driving AC generators. Averaging periods were days and six months, which corresponds two engine log-books. The average electrical power $N_{e s a}$ in the day was calculated from the formula:

$$
N_{e s a}=\frac{\sum_{i=1}^{i=n} E_{e i}}{\sum_{i=1}^{i=n} \tau_{i}},
$$

where $E_{e i}$-the $i$-th electric power of the generating set, $\tau_{i}$-the $i$-th time of the generator's work.

Figure 8 presents the average electric power values for documented changes in electricity based on the indications of electricity meters and the corresponding time intervals based on working hour counters of combustion engines driving generators for half a year.

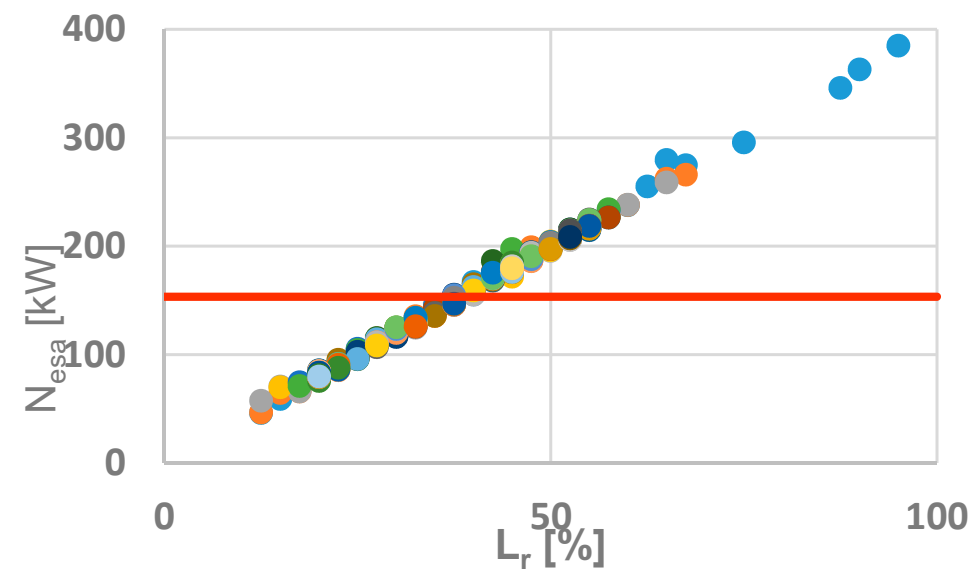

Figure 8. Systematized and averaged values of electrical power over time intervals for the corresponding relative loads:-average value of electric power. 
On this basis, histograms of the fraction of working times of generating sets for individual loads have been developed. Because the powers of piston internal combustion engines and generators varies, relative values were calculated and expressed as percentage. Example histograms of the electrical power share for individual loads of a generator set with a piston engine AL20/24 a synchronous generator is presented in Figure 9a. The average hourly load calculated in this way was even less for 6L16/24 engine, amounting to as little $36.33 \%$, and the most commonly occurring relative load was $36 \%$ Figure $9 \mathrm{~b}$. Figure 9 shows that small and medium loads of generating sets, and thus of piston internal combustion engines, are most frequent.

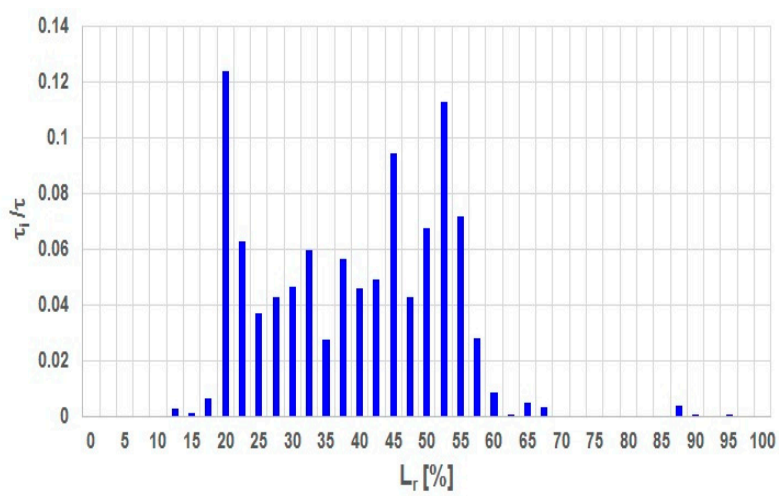

(a)

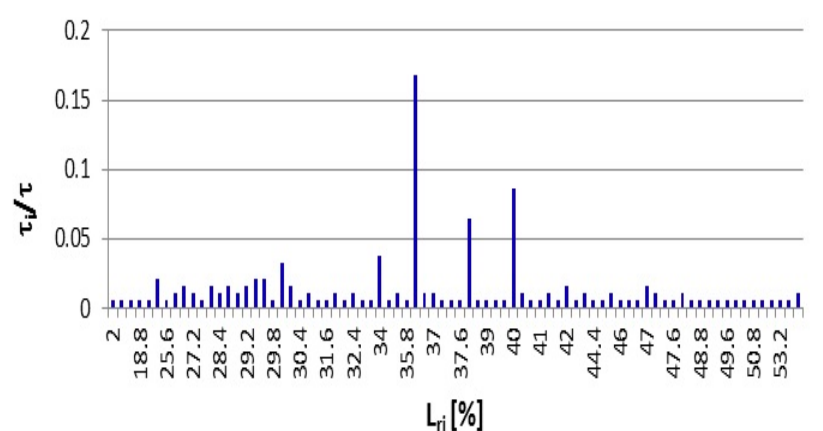

(b)

Figure 9. Histogram working times of generating sets at individual relative loads $L_{r}$ with the combustion engine from Wärtsilä (a) and MAN Energy Solutions company (b).

\subsection{Research on the Impact of Load on Diagnostic Parameter Values}

When planning the experimental research program, such measurement points were identified that research could cover the broadest possible could cover. Measurement points for the determination of load characteristics in laboratory conditions should be made for the following partial and nominal values of loads: $0 \%, 25 \%, 50 \%, 75 \%, 100 \%$, and $110 \%$. In operational investigations on seagoing ships, such load characteristics were checked during acceptance tests after periodical maintenances. However, the relative load was not always increased by $25 \%$, because it depended on the random possibilities of ship generator load changes. The literature mainly includes analyzes of pressure signals of working processes relating to the crankshaft rotation angle and time. In this work, the analysis of diagnostic signals were carried out in the domain of time, amplitude, frequency and as a wavelet analysis. Encouraging results in the frequency domain are shown here.

The analysis of diagnostic signals in the time domain allows us to obtain the time waveform of a single signal and averaged signals (up to $\mathrm{n}$ averages), and to define the start, end and the duration of the process. The signals were recorded as time waveforms using the time selection with an opening interval. As numerous available studies refer to time domain, this work only used this analysis for signals visualization.

In this work, the combustion process in a piston engine is assessed using simple, dimensionless amplitude estimates. Most of the point estimates are determined for a (single) instantaneous signal, and the values of simple estimates (average value, peak-crest value, peak to peak value, rms - root-mean-square values) were defined and presented in the publications $[7,40]$. The amplitude definitions given are in fact moments of the stationary modulus and the ergodic random process $S(\tau)$ [44]. Due to the random component in the observed process, each measure is averaged over the appropriate dynamic time interval $\tau$, with the interval $T$ (Hann [44] window) called the observation time. Selected dimensionless estimates of the processes were also used, calculated from point measures [44]: shape factor, crest factor and impulse factor. 
Since the fuel injection and puffing processes are periodic processes, it is important in the information processing to consider the spectrum for this class of signals. In the frequency domain, the signal $S(\tau)$ can be represented by its expansion into a Fourier series, which is equivalent to decomposing this function into simple periodic components. The process of decomposing a periodic function into simple components whose frequencies $f$ are a multiple of the fundamental frequency $f_{0}$, i.e., harmonic components [44], is called the harmonic analysis. When analyzed in the frequency domain, polyharmonic spectra of the complex periodic signal were obtained.

The analysis of in-cylinder pressure signals in the frequency domain is described. For the periodic pressure signal $P_{\mathrm{s}}(\tau)$ with any period of $T$ and an angular frequency meeting the Dirichlet conditions, the expansion into Fourier series has the form:

$P_{s}(\tau)=\frac{a_{o}}{2}+a_{1} \cos \omega_{0} \tau+b_{1} \sin \omega_{o} \tau+a_{2} \cos 2 \omega_{o} \tau+b_{2} \sin 2 \omega_{o} \tau+\ldots a_{n} \cos n \omega_{o}+b_{n} \sin n \omega_{o} \tau$,

where: $a_{0}, a_{n}, b_{n}$-coefficients, $\omega_{0}$-angular frequency.

The expansion of the relationship (17) can also be represented in a different form by substituting:

$$
a_{n}=\sqrt{a_{n}^{2}+b_{n}^{2}} \cos \varphi_{n}, \quad b_{n}=\sqrt{a_{n}^{2}+b_{n}^{2}} \sin \varphi_{n}=H_{n} \sin \varphi_{n}
$$

where $H_{p_{s}}=\sqrt{a_{n}^{2}+b_{n}^{2}}$ another component of the amplitude spectrum, $\varphi_{n}$-initial phase.

Figures 10 and 11 shows that the averaged spectrum contains many characteristic components for different frequency values. This is a banded spectrum that is graphically represented by lines with lengths proportional to the amplitudes $H\left(P_{s i}\right)$ of individual components of the frequencies $f_{o}, 2 f_{o}, 3 f_{o}, \ldots, n f_{o}$ [44]. Where $f_{o}$ is the rotational frequency of the crankshaft, which results from work the four-stroke low load engines.

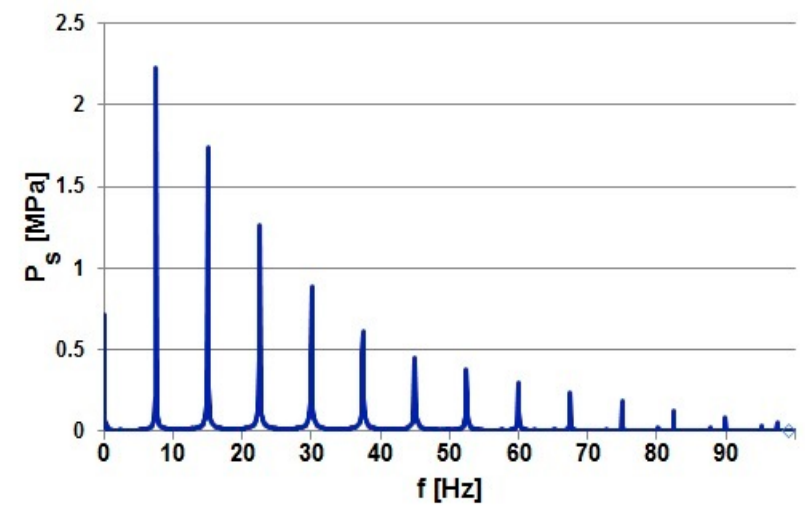

(a)

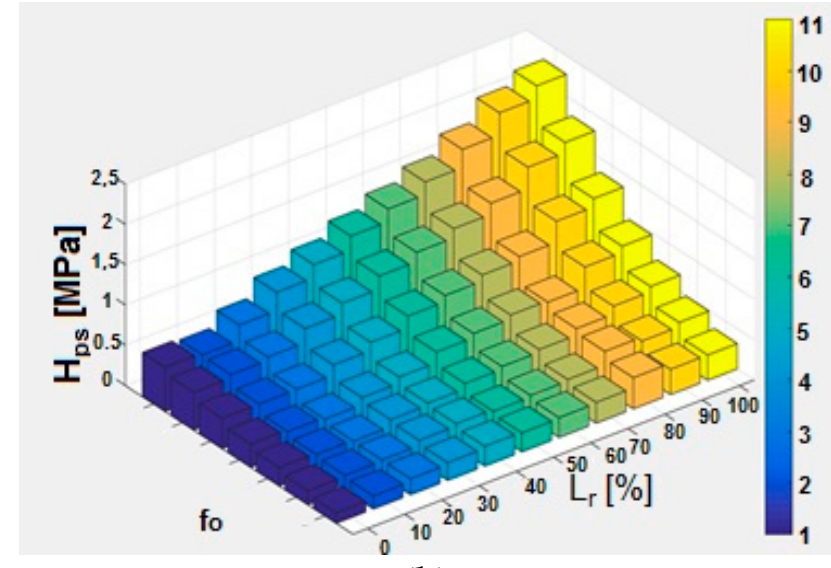

(b)

Figure 10. The spectrum of pressure in cylinder self-ignition engines in the frequency band $0-100 \mathrm{~Hz}$ (a) and the 3-D effect of the load on the value of the amplitudes of harmonics in the spectrum of in-cylinder pressures of a combustion engine (b).

Figure 10a presented an example polyharmonic spectrum of pressure in cylinder self-ignition engines in the frequency band $0-100 \mathrm{~Hz}$, and Figure $7 \mathrm{~b}$ presents the 3-D effect of the load on the value of the amplitude of harmonics in an in-cylinder pressure spectrum of a Wärtsilä engine. The analysis of signals in the $0-100 \mathrm{~Hz}$ band gives a better quality of the spectrum than the selected spectrum in this range from a larger frequency range (Figure 2c). The highest values of correlation and sensitivity coefficients between diagnostic parameters and input values were shown. 


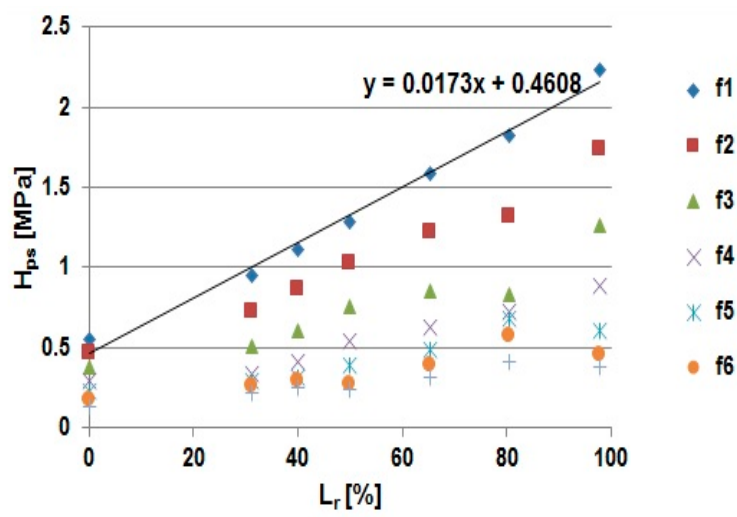

(a)

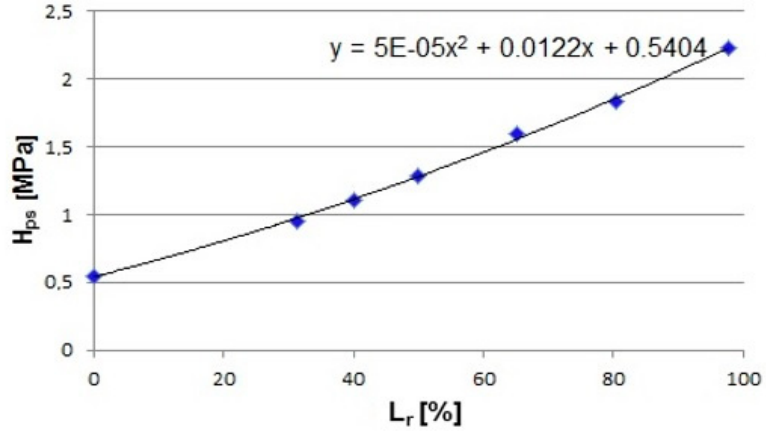

(b)

Figure 11. The impact of the relative load of the $L_{r}$ engine on values of the amplitudes of first seven harmonics of the in-cylinder pressure spectrum $H_{p s}(\mathbf{a})$ and amplitudes values of first harmonic of the in-cylinder pressure in the frequency band $0-100 \mathrm{~Hz}$ with approximation of the measuring points $(\mathbf{b}): f_{0}$-rotational frequency.

As a result of diagnostic experiments, $n$-measurements of two features: $Y$ and $X$, in the population are obtained. The aim is to estimate the dependence of the variable $Y$ diagnostic parameters on the input variable $X$. pairs of numbers $\left(X_{i}, Y_{i}\right)=\left(x_{i}, y_{i}\right)$, where $i$ numbers the units in the sample. Such pairs of numbers can be put on the coordinate system with the $X$ and $Y$ axes, producing the scatter plot. Then we select the most appropriate regression model [44] for the relationship describing the change in the expected value of quantity $Y$ with the change of quantity $X$, i.e., assign the form of the mathematical function that best "fits the reduced" image of the scatter plot. The most frequently used regression functions include [44]:

- linear function;

- polynomial function, mostly square;

- logarithmic function;

- exponential function;

- logistic function.

The selected diagnostic linear model is defined as follows: for the linear regression function, the two-dimensional distribution (the engine load or the technical state $X$ and diagnostic parameters $Y$ is normal or close to normal). From this population with an element sample, several results were obtained experimentally $\left(x_{i}, y_{i}\right)$. Based on the sample, the parameters of the linear regression function were estimated for using the least squares method of the form $\hat{y}=A x+\beta$. The least squares method gives the following estimate of the regression line:

$$
y=a x+b
$$

where: $a$ and $b$ were determined according to the formulas:

$$
a=\frac{\sum_{i=1}^{n}\left(x_{i}-\bar{x}\right)\left(y_{i}-\bar{y}\right)}{\sum_{i=1}^{n}\left(x_{i}-\bar{x}\right)^{2}}, \quad b=\bar{y}-a \bar{x}
$$

where: $\bar{x}$ and $\bar{y}$ mean values of $x$ and $y$ variables,

$y_{i}$ - value of the function $y=a x+b$ found according to the above formulas,

$\hat{y}_{i}-$ value of the estimated regression function $\hat{y}=a x+b$.

The estimators $a$ and $b$ are unbiased and consistent estimators of the parameters $A$ and $\beta$. The confidence area for a simple regression $y=A x+\beta$ limited by the confidence curves. Most of the phenomena occurring in real research objects are non-linear. Linear dependence is believed to occur in unique cases of simple objects or assuming simplifications in the 
accepted range of changes in input quantities $\left[x_{\text {imin }}, x_{\text {imax }}\right]$, where linearity is allowed in the theoretical analysis of the object. Linear polynomial can be written as:

$$
y=b_{0}+b_{1} x_{1}+b_{2} x_{2}+\ldots+b_{i} x_{i}
$$

The function of the object in the form of a linear polynomial can be determined by finding unknown values of the coefficients $b_{0}, b_{1}, \ldots, b_{i}$. The most frequently used method of approximation is the method of least squares [44].

In optimization studies, quadratic programming is nonlinear, and polynomials higher than 2 can be approximated by a simpler quadratic polynomial so that they are not a complex mathematical task. In diagnostic tests with many input quantities, a second order polynomial was often adopted, which can be reduced to a linear form using linearizing transformations.

Figure 11a shows the impact of the relative load of the $L_{r}$ engine on values of the amplitudes of first seven harmonics of the in-cylinder pressure spectrum $H_{p s}(\mathrm{a})$; Figure $11 \mathrm{~b}$ shows amplitudes values of first harmonic of the in-cylinder pressure in the frequency band $0-100 \mathrm{~Hz}$ of the 4L20D engine with approximation of measuring points by second order polynomial model.

With the increase of engine load the amplitude values in the spectra increase linearly, which was approximated by the linear model (Figure 11a) and the second-degree polynomial (Figure 11b). The second-degree polynomial model combines the amplitudes of the first component of the pressure spectrum in an engine cylinder with a relative load for the rotational frequency $f_{o}$ in the formula:

$$
H_{p s}=5 \mathrm{E}-05 L_{r}^{2}+0.0122 L_{r}+0.5404
$$

Research was also carried out also into parameters accompanying working processes where the relationships were non-linear $[7,40]$.

To assess the diagnostic usefulness of the amplitudes of the first seven spectral components of the cylinder pressure, the coefficient values of the correlation between them and the relative load of the engine were determined. Strong and very strong relationships were obtained with correlation coefficients in the range of 0.889 to 0.995 .

The $R^{2}$ determination coefficient was also used as a global measure of matching the regression model to the experimental data determined by the formula:

$$
R^{2}=\frac{S_{S T}}{S_{S R}}
$$

where: $S_{S T}$-total sum of squares, $S_{S R}$-part sum of squares due to regression.

The highest value of the determination coefficient $R^{2}=1$ was obtained for the polynomial sixth degree, higher than for the linear model $R^{2}=0.9893$. However, as the degree of the polynomial increases, the nonlinearity of the approximation line amplified.

To verify the method, the values of amplitudes of the first component in spectrum for the expected constant engine load in individual cylinders were presented. Testing was carried out for various engine cylinders before and after periodic maintenance. It was difficult to get to obtain repeated loads for each cylinder. Therefore, with the known model, the values of the diagnostic symptom were corrected from similar load values to one average load (Figure 11).

This demonstrated one way to cope with diagnostic difficulties related to marine internal combustion engines at changing operating conditions of seagoing ships. Figure $7 \mathrm{~b}$ shows the dynamics of load changes, while Figure 12 shows the values of deviations from the average percentage. The coefficient of variation of the diagnostic symptom was 0.0609 at 0.0428 for relative load, which is essential. 


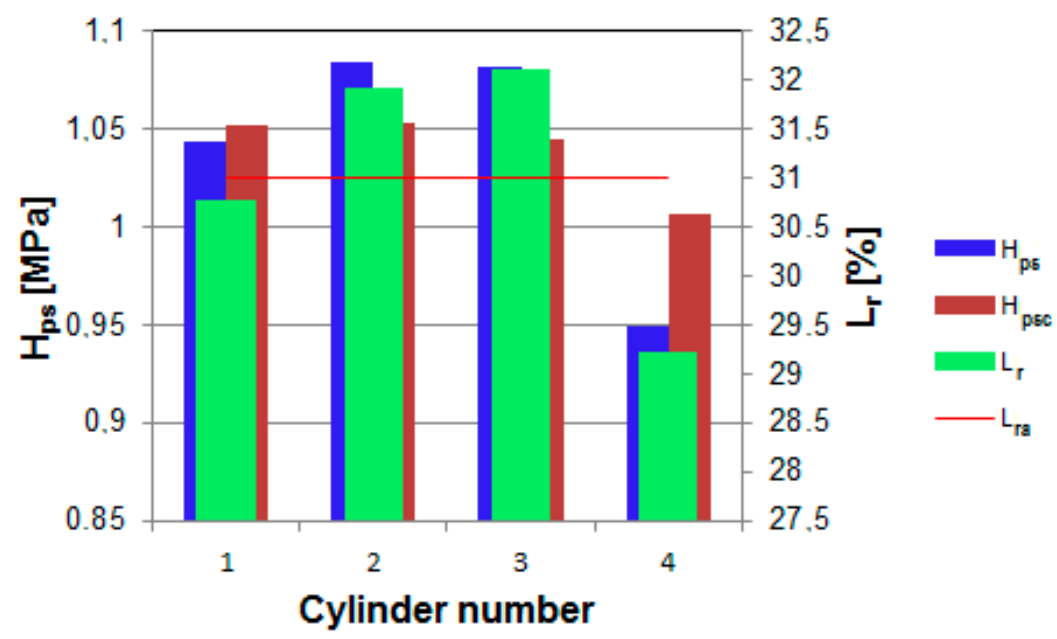

Figure 12. Values of the diagnostic symptom of in-cylinder pressure in the frequency domain $H_{p s}$ for similar relative loads $L_{r}$ of the engine and values of corrected amplitudes $H_{p s c}$ for the average load $L_{r a}$.

\section{Conclusions}

The above analysis showed that the examined engines are operated at low loads. These conditions were mostly determined at the design stage, and the operation of generator sets with low loads is has negative impact. Low load is often caused by operational situations, such as the irregular work of deck cranes and crew habits.

The experimental studies carried out authorize to formulate the following conclusions:

- it is possible to choose such diagnostic symptoms of the changes in working and residual processes that will correlate with the relative load and the technical state of the ship engine;

- values of diagnostic symptoms increase linearly and nonlinearly along with increasing value of with the increase in load;

- amplitudes of the components of the pressure spectrum in the cylinder are polyharmonic signals with frequencies that are multiples of rotational speed of crankshaft;

- spectral symptoms of pressure in the cylinder form very strong linear relationships with the engine load, which facilitates correction from one load to another;

- ship's piston engine should be diagnosed in steady-state conditions at constant load;

- diagnostic parameters registered for different loads can be converted to the common load of the internal combustion engine based on the model;

- control of the load status of the tested object can be carried out remotely in a ship using the wireless monitoring system with radio transmission of data.

The author's originality and contribution are the development of a method of visualizing the load of a generator set, whose electrical instruments, and recorders are located at a considerable distance from the machine. Another contribution is the use of atypical diagnostic symptoms-amplitudes of the components of the pressure spectrum in the cylinders of combustion engines, resistant to fluctuations in the constant component of the signal. We perform further experimental investigations to show the advantage of our methodology over others.

Funding: This research received no external funding.

Institutional Review Board Statement: Not applicable.

Informed Consent Statement: Not applicable.

Data Availability Statement: Data not shared.

Conflicts of Interest: The author declare no conflict of interest. 


\section{Abbreviations}

$A(r) \quad$ algorithm

$a_{o}, a_{n}, b_{n}, c, d$ coefficients

$C_{c} \quad$ coefficient of simultaneity

$C_{l} \quad$ load coefficient

$C_{o i} \quad$ operational factors of use of the installed capacity

$C_{S} \quad$ coefficient of simultaneous work of individual receivers

$C_{v} \quad$ fuel heating value

$D \quad$ cylinder bore

$d V \quad$ change of displacement volume

$F_{d} \quad$ power supply

$E_{e i} \quad$ the $i$-th electric power of the generating set

$F(\tau, \theta) \quad$ targeted action on the functioning of the diagnosed internal combustion piston engine

$\begin{array}{ll}f_{0} & \text { the rotational frequency of } \\ G_{e} & \text { fuel consumption per hour }\end{array}$

$H_{p_{s}} \quad$ component of the amplitude spectrum

$i \quad$ number of cylinders

$I_{q} \quad$ input signal vector

$I_{v} \quad$ interference quantities

$L_{r} \quad$ relative load

$L_{r a} \quad$ the average load of the generating set

$L_{r i} \quad$ value of the $i$-th load

$M_{c} \quad$ compressor torque

$M_{e} \quad$ engine torque

$M_{r} \quad$ receiver torque

$M_{t} \quad$ turbine torque

$N(\tau, \theta) \quad$ interference quantities that are not directly measured

$N_{e} \quad$ effective power

$N_{e c} \quad$ converting effective power

$N_{e l} \quad$ electric power

$N_{e n} \quad$ power rating of the receiver

$p_{e} \quad$ mean effective pressure

$p_{i} \quad$ mean indicated pressure

$P_{S} \quad$ cylinder pressure

$Q_{i} \quad$ heat supplied for the system

$Q_{0} \quad$ heat removed from the system

$r \quad$ spatial coordinate

$R^{2} \quad$ determination coefficient

$S \quad$ piston stroke

$S_{S R} \quad$ part sum of squares due to regression

$S_{S T} \quad$ total sum of squares

$S_{t} \quad$ steering

$T_{S} \quad$ technical sate

$z \quad$ work cyclical factor

$\mathrm{Z}(\tau, \theta) \quad$ measurable and non-controllable interference

conversion factor

initial phase

effective efficiency

efficiency of the electric generator

$\begin{array}{ll}\eta_{m} & \text { mechanical efficiency } \\ \theta & \text { time of object existence }\end{array}$

$\tau \quad$ dynamical time

$\tau_{i} \quad$ working time

$\omega_{0} \quad$ angular frequency 


\section{References}

1. Monieta, J. The Analysis of Load Marine Diesel Engines Type 6AL20/24 of Power Generators in the Difference Conditions of Swim, EXPLO-SHIP'99; Maritime University Szczecin: Szczecin, Copenhagen, 1999; pp. 109-114.

2. Wojnowski, W. Ship Power Plants, Designing Marine Power Plants. Examples of Engine Room Solutions; National Marine Fisheries Research Institute: Gdynia, Poland, 1994; Volume 3, pp. 14-109.

3. Takai, M.; Nishio, S.; Kuwabara, M. Load characteristics of high-speed marine diesel engines: Engine load characteristic and combustion analysis in service conditions. Mar. Eng. 2004, 3, 207-216. [CrossRef]

4. Boveri, A.; Silvestro, F.; GualenI, P. Ship electrical load analysis and power generation optimization to reduce operational costs. In Proceedings of the International Conference on Electrical Systems for Aircraft, Railway, Ship Propulsion and Road Vehicles \& International Transportation Electrification Conference (Esars-Itec), Railway, Toulouse, France, 2-4 November 2016; pp. 1-6. [CrossRef]

5. Wlodarski, J.K. Operating States of Marine Combustion Engines; University of Gdynia Maritime Publisher: Gdynia, Poland, 2001; pp. 77-98.

6. Tomaszewski, F.; Szymanski, G. Frequency analysis of vibrations of the internal combustion engine components in the diagnosis of engine processes. Arch. Transp. 2012, XXIV, 117-125. [CrossRef]

7. Monieta, J. Selection of Diagnostic Symptoms and Injection Subsystems of Marine Reciprocating Internal Combustion Engines. Appl. Scienc. 2019, 9, 1540. [CrossRef]

8. Serdecki, W. (Ed.) Research of Internal Combustion Engines; Publisher of Poznan University of Technology: Poznan, Poland, 2012; pp. 108-112.

9. Monieta, J. Reference characteristics of marine piston internal combustion engines. Sci. J. Pol. Nav. Acad. 2005, 162 K/2, 317-324.

10. Hountalas, D.T.; Papagiannakis, R.G.; Zovanos, G.; Antonopoulos, A. Comparative evaluation of various methodologies to account for the effect of load variation during cylinder pressure measurement of large scale two-stroke diesel engines. Appl. Energy 2014, 113, 1027-1042. [CrossRef]

11. Guerrero, D.P.; Jiménez-Espadafo, F.J. Torsional system dynamics of low speed diesel engines based on instantaneous torque: Application to engine diagnosis. Mech. Syst. Signal Process. 2019, 116, 858-878. [CrossRef]

12. Wu, J.; Duan, S.L.; Wu, Z.H.; Xing, H.; Liu, Q.A. The coupled thermal and mechanical load analysis in the 6S50MC-C type marine diesel's piston. Adv. Mater. Res. 2013, 690-693, 1909-1913. [CrossRef]

13. Hamilton, J.; Negnevitsky, J.M.; Wang, X. Low load diesel perceptions and practices within remote area power systems. In Proceedings of the 2015 International Symposium on Smart Electric Distribution Systems and Technologies (EDST), Vienna, Austria, 7-11 September 2016; pp. 121-126.

14. Monieta, J.; Sendecki, A. Database and knowledge about essential manufacturers of marine self-ignition engines. J. Mar. Sci. Eng. 2020, 8, 239. [CrossRef]

15. Brooks, P. Limitations on low load operation for fixed speed engines, marine application bulletin 2.05.00, Cummins. February 2015. Available online: https://gce.cummins.com/ace_aebs/aeb01017.pdf (accessed on 25 February 2020).

16. QSK78 (Tier 4 Final/Stage IV) I Cummins Inc. Available online: https://www.cummins.com \T1 \guilsinglrightengines $\backslash$ T1 $\backslash$ guilsinglrightqsk78-tier-4-finalstage-iv (accessed on 17 March 2020).

17. May, J.J.; Foss, H. Power management system for the "Deepwater Horizon" a dynamically positioned all weather semisubmersible. In Proceedings of the Dynamic Positioning Conference, Houston, TX, USA, 17-18 October 2000.

18. Piotrowski, I.; Witkowski, K. Marine Diesel Engines; Trademar: Gdynia, Poland, 2004; pp. 118-131.

19. Mrzljak, V.; Žarković, B.; Prpić-Oršić, J. Marine slow speed two-stroke diesel engine-Numerical analysis of efficiencies and important operating parameters. Int. Sci. J. Mach. Technol. Mater. 2017, 10, 481-484.

20. Anderson, M.; Salo, K.; Hallquist, Å.M.; Fridell, E. Characterization of particles from a marine engine operating at low loads. Atmos. Environ. 2015, 101, 65-71. [CrossRef]

21. Marine diesel engine emission standards agency; Environmental Protection Agency. Action: Proposed Rule. Federal Register. The Daily Journal of the Unites Government; 2019. Available online: https:/ / federalregister.gov/d/2019-19092 (accessed on 13 March 2020).

22. Michalopoulos, P.; Kanellos, F.D.; Tsekouras, G.J.; Prousalidis, J.M. A method for optimal operation of complex ship power systems employing shaft electric machines. IEEE Trans. Transp. Electrif. 2016, 2, 547-557. [CrossRef]

23. Radan, D.; Johansen, T.A.; Sorensen, A.J.; Adnanes, A.K. Optimization of load dependent start tables in marine power management systems with blackout prevention. Trans. Circuits Syst. 2005, 4, 1861-1866.

24. Liang, H.; Han, B.; Zhang, D. Research on control strategy of marine diesel engine in a hamiltonian framework. In Proceedings of the 36th Chinese Control Conference, Dailian, China, 26-28 July 2017; pp. 6330-6335. [CrossRef]

25. Balcerski, A. Ship's Power Industry. In Probabilistic Models in the Theory of Design of the Marine Combustion Power Plant; Foundation for the Promotion of Shipbuilding and Maritime Economy: Gdansk, Poland, 2007.

26. Giernalczyk, M.; Górski, Z. Marine Power Plants. Part 1, Fundamentals of Propulsion and Marine Power; Maritime University of Gdynia: Gdynia, Poland, 2016; pp. 24-59.

27. Giernalczyk, M.; Górski, Z. Analysis of trends in energy demand for main propulsion, electric power and auxiliary boilers capacity of tankers. J. Pol. CIMAC 2010, 5, 51-57. 
28. Satpathi, K.; Balijepalli, M.; Ukil, A. Modeling and real-time scheduling of dc platform supply vessel for fuel efficient operation. IEEE Transprtion Transp. Electrif. 2017, 3, 762-778. [CrossRef]

29. Giannoutsos, S.V.; Manias, S.N. Development of an integrated energy efficiency control system for ship power balance and diesel generator fuel consumption optimization. IEEE Ind. Appl. Soc. Annu. Meet. 2013, 1-11. [CrossRef]

30. IMO Marine Engine Regulations. Available online: https://dieselnet.com/standards/inter/imo.php\#intro (accessed on 13 March 2020).

31. Sørensen, A.J. Structural issues in the design and operation of marine control systems. IFAC J. Annu. Rev. Control 2005, 29, 125-149. [CrossRef]

32. Cuculic, A.; Vučetic, D.; Prenc, R.; Celic, J. Analysis of energy storage implementation on dynamically positioned vessels. Energies 2019, 12, 444. [CrossRef]

33. Barelli, L.; Bidini, G.; Buratti, C.; Mariani, R. Diagnosis of internal combustion engine through vibration and acoustic pressure non-intrusive measurements. Appl. Therm. Eng. 2009, 29, 1707-1713. [CrossRef]

34. Shahid, S.M.; Jo, B.; Ko, S.; Kwon, S. Real-time classification of diesel marine engine loads using machine learning. Sensors 2019, 19, 3172. [CrossRef]

35. Tuffaha, M.; Gravdahl, J.T. Modeling and control of a marine diesel engine driving a synchronous machine and a propeller. In Proceedings of the IEEE Conference on Control Applications (CCA), Part of Multi-conference on Systems and Control, Antibes, France, 8-10 October 2014; pp. 897-904. [CrossRef]

36. Zadrag, R. Supporting the empirical research on diesel engines with multi-equation models. Advances in Mechatronic Systems, Mechanics and Materials Book Series: Solid State Phenomena 2013, 196, 74-81.

37. Lamaris, V.; Hountalas, D. A general purpose diagnostic technique for marine diesel engines-Application on the main propulsion and auxiliary diesel units of a marine vessel. Energy Convers. Manag. 2010, 51, 740-753. [CrossRef]

38. Guan, C.; Theotokatos, G.; Chen, H. Analysis of two stroke marine diesel engine operation including turbocharger cut-out by using a zero-dimensional model. Energies 2015, 8, 5738. [CrossRef]

39. Başhan, V.; Demirel, H. Evaluation of critical operational faults of marine diesel generator engines by using DEMATEL method. J. ETA Marit. Sci. 2018, 6, 119-128. [CrossRef]

40. Monieta, J. Diagnostics of work process course in cylinders of marine reciprocating internal combustion engines using vibration signal. Combust. Engines 2013, 3, 153-160.

41. Pietak, A. Operation of the engine with SI conditions of dynamically changing loads. In Diagnosis of CI Engines Based on Transient Processes; Habilitaion Dissertation, Poznan University of Technology: Poznan, Poland, 1999; pp. 21-34.

42. Baldi, F.; Theotokatos, G.; Andersson, K. Development of a combined mean value-zero dimensional model and application for a large marine four-stroke Diesel engine simulation. Appl. Energy 2015, 154, 402-415. [CrossRef]

43. Chena, P.; Taniguchib, M.; Toyotab, T.; He, Z. Fault diagnosis method for machinery in unsteady operating condition by instantaneous power spectrum and genetic programming. Mech. Syst. Signal. Process. 2005, 19, 175-194. [CrossRef]

44. Żółtowski, B.; Cempel, C. Elements of the theory of technical diagnostics. In Engineering of Diagnostics Machines; Society of Technical Diagnostics: Warsaw, Poland; Bydgoszcz, Poland; Radom, Poland, 2004; pp. 17-525. 